\title{
Acquiring reading and vocabulary in Dutch and English: the effect of concurrent instruction
}

\author{
Aryan van der Leij · Judith Bekebrede • \\ Mieke Kotterink
}

Published online: 13 October 2009

(C) The Author(s) 2009. This article is published with open access at Springerlink.com

\begin{abstract}
To investigate the effect of concurrent instruction in Dutch and English on reading acquisition in both languages, 23 pupils were selected from a school with bilingual education, and 23 from a school with education in Dutch only. The pupils had a Dutch majority language background and were comparable with regard to social-economic status (SES). Reading and vocabulary were measured twice within an interval of 1 year in Grade 2 and 3. The bilingual group performed better on most English and some of the Dutch tests. Controlling for general variables and related skills, instruction in English contributed significantly to the prediction of L2 vocabulary and orthographic awareness at the second measurement. As expected, word reading fluency was easier to acquire in Dutch with its relatively transparent orthography in comparison to English with its deep orthography, but the skills intercorrelated highly. With regard to cross-linguistic transfer, orthographic knowledge and reading comprehension in Dutch were positively influenced by bilingual instruction, but there was no indication of generalization to orthographic awareness or knowledge of a language in which no instruction had been given (German). The results of the present study support the assumption that concurrent instruction in Dutch and English has positive effects on the acquisition of L2 English and L1 Dutch.
\end{abstract}

Keywords Bilingual education · Primary school · L1 Dutch · L2 English · Orthography $\cdot$ Reading acquisition $\cdot$ Loanwords

A. van der Leij $(\bowtie) \cdot$ J. Bekebrede $\cdot$ M. Kotterink

Department of Education, University of Amsterdam, P.O. Box 94208, 1090 GE Amsterdam,

The Netherlands

e-mail: D.A.V.vanderleij@uva.nl 


\section{Introduction}

Although L2 English proficiency of Dutch people is generally high, most Dutch children do not receive substantial formal instruction in English reading and language before they enter secondary school at the age of 12 . However, some primary schools provide English language lessons in Kindergarten and reading lessons in Grade 1 and onwards in order to give Dutch majority language children the opportunity to learn English at an early age. The present study investigates the effects of concurrent bilingual instruction on L1 Dutch and L2 English reading and vocabulary in comparison to single language instruction in the period from Grade 2 to Grade 3. Another question explored is whether experiences with English, which has a deeper orthography than Dutch, may result in better orthographic awareness that transfers to the L1 (Dutch) or even to a language in which no instruction had been given (German).

Studies of children's reading progress in bilingual programs indicate that cognitive skills transfer across languages and that L1 cognitive, linguistic and reading skills predict progress in learning to read in a second language (e.g., Comeau, Cormier, Grandmaison, \& Lacroix, 1999; Cisero \& Royer, 1995; Durgunoğlu, Nagy, \& Hancin-Bhatt, 1993; Gottardo, Yan, Siegel, \& WadeWoolley, 2001; Lindsey, Manis, \& Bailey, 2003; Riccio et al., 2001). It therefore seems fair to say that the basic skills in the native language provide the foundation for learning a foreign language, as was originally hypothesized by Ganschow, Sparks, Javorsky, Pohlman, and Bishop-Marbury (1991). For example, phonological processing, the efficient use of orthographic knowledge, and verbal memory capacity contribute to the transfer of reading related skill across languages (Geva \& Siegel, 2000).

As a consequence, concurrent instruction in reading in L1 and L2 will result in reading acquisition in both languages, predicted by the same basic processing skills. However, the rate of acquisition of reading skills in languages with comparable alphabetic principles varies with orthographic depth. In a monolingual context, the study of Seymour, Aro, and Erskine (2003) has indicated that reading acquisition by native speakers in the majority of European languages is characterised by high levels of accuracy of reading simple words at the end of first grade, independent of familiarity with the words. There are exceptions however, notably reading acquisition in French, Portuguese, Danish, and, particularly, in English. The authors suggest that the effects are attributable to fundamental linguistic differences in syllabic complexity and orthographic depth. For the purpose of the present study it is important to note that Dutch and English are comparable in syllabic structure but differ in orthographic depth. Dutch orthography has more or less a medium position on the scale between shallow and deep, whereas English orthography is an outlier on the far deep side (Seymour et al., 2003; Borgwaldt, Hellwig, \& de Groot, 2005; van den Bosch, Content, Daelemans, \& de Gelder, 1994; see also Share, 2008). In Grade 1, the rate of reading development in English is about twice as slow as in Dutch. As a consequence, Dutch pupils read above $90 \%$ of the words correctly at the end of the first year of formal reading instruction (Grade 1), whereas the English speaking pupils read only $34 \%$ at the same time, and are still below first grade Dutch accuracy level 
at the end of Grade 2 (80\%). Seymour et al. (2003) have suggested that the deeper orthographies create a dual foundation which takes more than twice as long to establish as the single foundation required for the learning of a shallow orthography. In addition to the alphabetic principle of single grapheme-phoneme conversions which is sufficient to phonologically decode most of the one-syllable Dutch words, many one-syllable English words need to be recognised by using a logographic process, i.e., the matching of larger orthographic units with sound strings.

The question we are concerned with is how differences in orthographic depth may affect reading when two languages are instructed concurrently. If reading acquisition is primarily a function of general underlying cognitive processes, it may develop relatively independent of orthographic differences between the languages (the "central processing hypothesis"). Alternatively, reading acquisition may vary as a function of orthographical transparency and may be easier when the script is less complex (the "script dependent hypothesis"). These contrasting hypotheses were formulated and explored by Geva and Siegel (2000). They concluded that the hypotheses are complementary rather than opposite. If the orthography is less complex, young children appear to pick up the word recognition skills with greater ease. With a more complex orthography, this takes more time, even in the first language, leading to a difference in rate of mastery in the first phases of the acquisition process. At the same time, individual differences in underlying cognitive skills have an effect on reading acquisition, independent of orthographic depth. According to this view, concurrent instruction will result in correlated reading acquisition in either language but at a faster rate in L1 Dutch than in L2 English.

Difference in acquisition rate does not necessarily imply that concurrent instruction and practice puts an extra burden on the learning process, or even slows down the learning process in L1 in comparison to single language instruction. In their study, Geva and Siegel (2000) could find no sign that the acquisition of a more complex orthography-English-interfered with the acquisition of a more transparent orthography (Hebrew). Bialystok, Luk, and Kwan (2005) who compared Cantonese-English, Hebrew-English and Spanish-English bilinguals to English monolinguals, have shown that concurrent instruction leads to a general increment in reading ability in both languages. However, the cross-linguistic effect on reading ability was larger when the two languages share the same writing system, i.e., when both were alphabetic languages. Because the two languages of the present study share both a syllabic complexity and an identical alphabetic writing system, it may be expected that young Dutch children who receive concurrent instruction and practice in Dutch and English reading will show higher proficiency in both languages than Dutch children who receive instruction and practice in their native language only.

To support this expectation, Bialystok et al. (2005) suggested that the need to cope with the challenge to learn to read two languages enhances the awareness of strategies and stimulates the use of expertise build up in both languages, resulting in a general proficiency in reading of the bilingually instructed children. Possibly, the confrontation with a language with a considerable orthographic depth enhances orthographic awareness because English puts higher demands on logographic processing than Dutch. Although Dutch has a relatively transparent orthography, in 
particular with regard to one-syllable words, quite a few multisyllabic words need to be recognised using larger orthographic units than grapheme-phoneme correspondences (van der Leij \& van Daal, 1999). Experience with English logographic processing may facilitate cross-linguistically the recognition process of multisyllabic words in L1. This idea received support in a study conducted by Morfidi, van der Leij, de Jong, Scheltinga, and Bekebrede (2007) who investigated the L1 and L2 language and reading ability of Dutch students after they started to learn English as a second language at the secondary school (Grade 7 and upwards). Supporting the "central processing" hypothesis, analyses revealed that fluency of word reading predicted its counterpart from Dutch to English and vice versa. Without the related L2 reading predictor and in addition to L2 rapid serial naming, English orthographic knowledge explained a small amount of unique variance in Dutch word reading fluency, indicating a "learner-by-script" interaction in line with the conclusions of Geva and Siegel (2000). Discussing their findings, Morfidi et al. (2007, p. 778) suggested: "learning a less transparent orthography such as English may put a heavy demand on learning mechanisms that are also important in learning a more transparent orthography but stay hidden under the strong influence of general reading efficiency that is based on phonological decoding." Possibly, learning to read English concurrently, with its heavy load on logographic processing, leads young Dutch learners to an increased awareness of logographic principles. In turn, this awareness may transfer to the first language, resulting in an advantage of bilingually instructed children in L1 reading in comparison to children in a monolingual context. To explore whether there may even be a more general effect of increased orthographic awareness, the present study also included orthographic skills in a third language-German-in which no instruction had been given.

The Netherlands as a linguistic environment

To understand the context of the study, it is important to note that The Netherlands, although inhabited by a population of about 16.5 million, is geographically a small country $\left(35,000 \mathrm{~km}^{2}\right)$. Dutch is spoken in The Netherlands and in roughly half of Belgium by about 23 million people. In comparison, German is spoken by about 110 million people, whereas the number of English speakers is comparably enormous. In combination with the tradition of The Netherlands as an open society with a lot of international trade and traffic, the relative smallness of the language area requires that Dutch people learn foreign languages. Up to the 1970s, English, French and German were obligatory subjects in secondary school. Today, English is still obligatory, whereas other languages are often chosen as elective subjects.

English is not only learned in the secondary school context. Recently, some English lessons have been introduced in Grades 5 and 6 of the primary school. In a more informal way English is very common in everyday life, at least passively. On Dutch television and in the movie theatres, English spoken films are subtitled in Dutch, leaving the original spoken language intact. The music industry with its large production of English songs, adds to the familiarity with English, in particular of young children and adolescents who spend a lot of time listening to popular music. Moreover, the use of computer language (software, games, and internet) contributes 
to the familiarity of English. The influence of English as the dominant world language can also be measured by the amount of loanwords that have become part of the Dutch vocabulary. For example, words such as tram, computer, software, and goal are integrated into the Dutch language, pronounced as English words and, in written form, are not adapted to Dutch orthographic rules. In such an L2-English friendly environment, it may be assumed that young pupils gather a lot of English knowledge in everyday life even without explicit instruction and practice.

\section{Research questions and expectations}

The central research question of our study concerned the effect of concurrent bilingual instruction on L1 Dutch and L2 English reading and vocabulary in comparison to single language instruction. Our first prediction was that bilingual instruction and practice lead to an increase of L2 skills. Measures of L2 vocabulary, word reading fluency, orthographic knowledge and awareness, and fluency of reading English loanwords were used to test this prediction. Secondly, it was expected that the rate of progress in word reading fluency would be slower in L2 English with its more complex orthography than in L1 Dutch, indicating the effect of script-dependency. However, the skills would be highly intercorrelated, supporting the central processing hypothesis at the same time. Thirdly, it was expected that bilingual instruction would have a positive effect on reading across languages. This expectation could only be supported by a positive effect on the first language in comparison to a control group that only received single language instruction. In particular, as a consequence of a general enhancement of awareness of strategies and expertise, the bilingual group was expected to perform better than the monolingual group in L1 reading skills (a "learner-by-script interaction", see Geva \& Siegel, 2000). Increased orthographic awareness could then be used to understand some of the orthographic rules that imply logographic processing in Dutch multisyllabic words but are less frequently taught and practiced. In addition it was investigated whether "the efficient use of orthographic knowledge" (Geva \& Siegel, 2000) could have an effect on orthographic awareness of a third language in which no instruction had been given. To explore this question, orthographic awareness of German was included in the study. German was chosen because the schools are situated in a city (Enschede) near the German border. It may be assumed that the pupils at least had some exposure to the German language, for example by watching German television (in Germany English spoken films are not subtitled but synchronised with German voices), or by cross-border traffic. However, the pupils had received no formal instruction in German at school.

It should be noted that one of the limitations of the present study is that there was no pretest measurement when bilingual or single language instruction and practice started in Kindergarten, nor at the start of formal reading instruction in Grade 1. However, progress over time was studied because the participants were assessed twice within an interval of 1 year: halfway through Grades 2 and 3, respectively. If continued bilingual instruction and practice affects development, it was expected to enhance differences between measurements. 


\section{Study design}

In the Netherlands, preschool, Kindergarten and primary school are integrated in the Basisschool (Primary School) with Grades (groepen: 'groups') 1-8 for 4-12 year olds. In this paper the international equivalent will be used with Grade one as the first grade with formal instruction and practice of reading and other academic skills (group 3 of the Basisschool). A group of pupils, attending one class of one school, was selected to receive concurrent instruction in Dutch (L1) and English (L2) from the day they entered the Basisschool at the age of four, and in L1 and L2 reading 2 years later in Grade 1 (the bilingual group). At the time of the first measurement halfway through Grade 2, they were acquainted with English as a spoken language for about 3.5 years, and as a written language for about 1.5 years. The other group of pupils-attending one class of another school—did not receive any instruction or practice in English, at least not formally at their school (the monolingual group). The two groups were comparable on Dutch origin, social-economic background, age and sex, and L1 skills that have shown to affect reading acquisition (phoneme awareness and vocabulary). A variety of tasks measuring reading and vocabulary in L1 (Dutch) and L2 (English) was used, for the most part chosen or developed as parallel tests, using the experience we have gathered with Dutch-English comparisons at the secondary level of schooling (see Morfidi et al., 2007). To measure progress, the measurement was repeated after a year.

\section{Method}

\section{Participants}

At the beginning of the study, 52 primary school pupils were selected of which 27 were from a primary school with bilingual education and 25 from a monolingual primary school with only native language education. Within an interval of 1 year, there were two measurements (Grade two and Grade three, both in January-March). Because of movement to another school, retention, and referral to Special Education, 6 pupils missed the second measurement. For a straight comparison of the results, these pupils were removed from the data of the first measurement (T1). At T1, the average chronological age of the pupils from the bilingual school was 97.30 months $(\mathrm{SD}=6.09)$, and from the monolingual school 94.74 months $(\mathrm{SD}=5.37)$. At the second measurement (T2), the average chronological age was 12 months higher. There were 10 boys and 13 girls, and 9 boys and 14 girls in the bilingual and monolingual groups, respectively. All pupils spoke Dutch as their first language. The schools were matched with regard to population. Socialeconomic status, and in particular, educational level of the parents, was comparable. Most parents had at least completed secondary school, and had also received additional education. The schools were marked as 'middle and upper class', and received no extra funding for low SES pupils, according to the Dutch system. As another indication of comparability, the schools were similar in terms of the level of outflow to secondary schools. 
Bilingual instruction

At the bilingual school English is incorporated into the normal curriculum. The children receive English lessons from kindergarten (age 4) to the end of primary school (age 12). The main focus in Grade 2 is on verbal communication and in Grade 3 on spelling ability. However, the total number of hours spent on language and reading lessons is comparable to the majority of the schools with a single language curriculum, including the monolingual control school. In the 4 years from Kindergarten to Grade two (called group 1-4 in the integrated Dutch system) the children have 5, 20-25 min, English lessons a week. The introduction of English is done in a playful manner adapted to this age. In Grades three to six (group 5-8) they receive 4, $30 \mathrm{~min}$, lessons a week. In the higher grades the lessons are more formal and English is the language of instruction in other content area lessons.

\section{Measures}

In addition to Dutch tests of phoneme awareness and reading comprehension, similar versions of tasks measuring vocabulary, word reading fluency, orthographic knowledge, and orthographic awareness in Dutch (L1) and English (L2) were used. In addition, German orthographic knowledge and awareness tasks (L3) were constructed.

\section{Dutch}

Dutch Vocabulary L1 (CITO, Verhoeven, 1993a). The pupil's receptive vocabulary in L1 is tested in Grade 2 by means of a standardised vocabulary test (developed by CITO = Central Institute for Test Development). The test consists of 50 items. Four pictures per item are portrayed. The tester says a word and the pupil must point to the correct picture. The score is determined by the number of correct answers. Reliability is reported by the author to be $>.90$.

Phoneme awareness L1. A computerized task (Bekebrede, van der Leij, \& Share, 2009) was used to measure phoneme awareness in Grade 2. This subtest was originally developed by Buis and Charles (1996). The pupils hear two pseudowords (e.g., ket-tek). They have to indicate whether the second word is the reverse of the first. The word reversal task consists of 6 examples and 30 items. All items are monosyllabic pseudowords with one or two consonants at the beginning or at the end of the word. The internal consistency (Cronbach's alpha) of this experimental task was .72 for Grade 2.

Word Reading Fluency L1 (EMT). Een-Minuut-Test [One Minute Test] (Brus \& Voeten, 1973) is a standardised Dutch test measuring general word reading fluency with 116 words of increasing difficulty, divided over four columns. The participant is asked to read aloud as many words as possible in $1 \mathrm{~min}$. Accuracy and speed are of importance. The test score is the number of words read correctly in $60 \mathrm{~s}$. The test is administered both in Grade 2 and 3. Parallel test and test-retest reliabilities are reported to be over 80 (van den Bos et al. 1994).

Word Reading Fluency Ll (DMT). Drie-Minuten-Test [Three-Minute-Test] (Verhoeven, 1995). The DMT is another standardised Dutch test, measuring fluency 
of word reading in the same way as EMT. To measure fluency of reading multisyllabic words, only card 3 was used (the other two contain one-syllable words. The card is made up of four columns with 30 words in each column with two, three and four syllables. The task is to read as many words as possible, correctly, from each card within $1 \mathrm{~min}$. The score is the number of read words minus the number of incorrectly read words. Reliability (Cronbach's alpha is reported to be $>.90$ (Moelands, Kamphuis, \& Verhoeven, 2003).

Orthographic Knowledge L1. To measure orthographic knowledge in the participants' native tongue, van der Leij and Morfidi (2006) developed a Dutch adaptation of the English orthographic knowledge task of Olson, Forsberg, Wise, and Rack (1994). The items are based on Assink and Kattenberg's (1994) six categories of spelling difficulty in Dutch (analogy, congruence, etymology, double vowels or consonants, pronunciation options and spelling of loanwords). Forty pairs of homophonic words (e.g., hoet-hoed [hat]; second leg is the right one) are presented on an A4-format page. The participants are asked to choose the correctly spelled word in each pair. The test is administered in both Grade 2 and 3. The internal consistency (Cronbach's alpha) was found to be .68 (Bekebrede et al., 2009). See van der Leij and Morfidi (2006) for the list of items.

Orthographic Awareness L1. A test of Siegel, Share, and Geva (1995) has been adjusted to Dutch language and to the age of the pupils (experimental task). The pupils are given 17 pairs of pronounceable Dutch pseudowords and asked which item in each pair can possibly be a correctly spelled word. One of the two words in each pair is made up of a letter combination (at the beginning or at the end of a word) that never occurs in Dutch, for example the second leg of jors-jorz. The correct word has to be underlined and the score is the number of correctly underlined items. Orthographic awareness in Dutch is only administered in Grade 3 (see Appendix A for the items). No test-retest reliability has been investigated yet.

Reading Comprehension L1 (Schaal Betekenis Relaties [Scale relations between meanings]; Verhoeven, 1993b) is a standardized classroom test that examines to what extent contextual connections are made between parts of a text. The test contains six short stories, each of which is followed by a set of questions covering the meaning of words, the meaning of a sentence, cross relationships, relations between sentences and the thematic meaning of the text. The score is the number of correct answers. Reliability is reported to be $>.90$. This test was taken at $\mathrm{T} 1$ only because it is only suitable for use in Grade 2. At T2 in Grade 3, reading comprehension was measured using stories and questions from a reading comprehension test in the Dutch pupil monitoring system (from CITO, M4) (Staphorsius \& Krom, 1998). Scores are reported in terms of number of correct answers. Reliability is reported to be $>.90$ (Staphorsius, Krom, Kleintjes, \& Verhelst, 2004).

\section{English}

English Vocabulary. Half of the items (69) of the English version of the Peabody Picture Vocabulary Test (PPVT, Dunn \& Dunn, 1981) are presented on a computer screen (Bekebrede et al., 2009). Four pictures are shown, of which one picture matches the word that was spoken. The pupil has to point to the matching picture. 
The score is the number of correct items. This vocabulary test is administered in both Grade 2 and 3. Cronbach's alpha was .89 and .88, respectively, for Grade 2 and 3.

Word Reading Fluency L2 (OMT) [One Minute Test, OMT]. The English One Minute Test (Fawcett \& Nicolson, 1996) is a standardised test that has been developed by the authors as an equivalent of the Dutch EMT (see above). It measures general fluency of word reading in English. The test consists of 120 words of increasing length. The test score is the number of words read correctly in $1 \mathrm{~min}$. The pronunciation of the English words has to be the English pronunciation. It is not acceptable to use the Dutch grapheme-phoneme correspondence rules. The OMT is administered both in Grade 2 and 3. Fawcett and Nicolson have reported test-retest reliability of .99 .

Loanword Reading Fluency (Schijf, 2006). This experimental test is also modelled after the EMT (and, thus, also related to the OMT) with respect to aim, length and increasing length of the words. Loanwords are English words that have been adopted in the Dutch language. Pupils are asked to read as many of these words as possible within $1 \mathrm{~min}$. The test consists of 116 words of increasing length, examples: team, snackbar, taperecorder (printed as one word). The score consists of the number of correct words read in $1 \mathrm{~min}$. The pronunciation of the English loanwords had to be faithful to the pronunciation of a native English speaker. It was not acceptable to use the Dutch grapheme-phoneme correspondence rules (not the Dutch pronunciation). This task is administered only in Grade 3. Test-retest reliability is not yet reported for this experimental task.

Orthographic Knowledge L2. This test is the original test of Olson et al. (1994) evaluating orthographic knowledge in English. Forty pairs of words (e.g., wurdword) are presented on an A4-format page. The participants are required to choose the correctly spelled word in each pair. Both accuracy and time are recorded. This orthographic choice task is administered both in Grades 2 and 3. Internal consistency (Cronbach's alpha) was found to be .76 (Bekebrede et al., 2009). See van der Leij and Morfidi (2006) for the list of items.

Orthographic Awareness L2. The test of Siegel et al. (1995) has been adjusted to the age of the pupils (experimental task). The pupils are given 17 pairs of pronounceable English pseudowords and asked to underline the word in each pair that can be an acceptable word according to orthographic conventions. One of the two words is made up of a letter combination (at the beginning or at the end of a word) that never occurs in English, for example the first leg of filv-filk. The score is the number of correctly underlined items (see Appendix A for the items). This task is only administered in Grade 3. No test-retest reliability has been investigated yet.

\section{German}

Orthographic Knowledge L3. To measure orthographic knowledge in German in Grade 3 a German version with 20 items of the orthographic choice task of Horsley (2005) has been developed (experimental task). Out of three alternatives, the correctly spelled word has to be underlined e.g., Fuss-Foes-Voess (Fuss is the right one). To reduce the effect of chance, three answer-options are developed. The score 
is the number of correctly underlined items (see Appendix B for the items). Testretest reliability is not yet reported for this experimental task.

Orthographic Awareness L3. Similar to the orthographic awareness tasks in L1 and L2, administered in Grade 3, the pupils are given 17 pairs of pronounceable German pseudowords and asked which item in each pair can be an acceptable word according to orthographic conventions. One of the two words is made up of a letter combination (at the beginning or at the end of a word) that never occurs in German, for example the second leg of Dolz-Dolj. The correct word has to be underlined and the score is the number of correctly underlined items (see Appendix A for the items). No test-retest reliability of this experimental task has yet been investigated.

\section{Procedure}

After selection of the schools and obtaining consent from the parents, the individual tests were administered in a standard order, the Dutch tests first, followed by the English tests. All tasks with oral responses were tape-recorded. The required time was approximately $50 \mathrm{~min}$ per pupil, divided into two sessions. The group tests (all tests that did not involve an oral response) were supervised by the group teacher. The tests were taken in the period from January to March at both measurements (Grades 2 and 3). The German tests were was assessed at T2 only.

\section{Data analysis}

The computer program SPSS 12.0 was used for input and statistical processing of the data. To compare the groups, the scores were entered into a multivariate analysis of variance (MANOVA) with the tests as dependent variables and the two groups (monolingual/bilingual) as independent variables. The reported effect size is the $\eta_{p}^{2}$, which reflects the proportion of variance in the effect of interest plus error variance attributable to the effect of interest $\left[\eta_{p}^{2}=\mathrm{SS}_{\text {effect }} /\left(\mathrm{SS}_{\text {effect }}+\mathrm{SS}_{\text {error }}\right)\right]$. In interpreting the $\eta_{p}^{2}$, an effect size of .01 is considered small, .06 medium and .14 large (Cohen, 1977; see Stevens, 2002, p. 197, and Tabachnick \& Fidell, 2007, p. 55).

To test the second expectation about differences in progress in L1 and L2 word reading fluency of the bilingual group, interaction analyses were performed with language (L1 and L2) and time (T1 and L2) as independent variables.

Because the design did not include a pre-test at the start of reading instruction, but included a measurement wave in Grades 2 and 3, we decided to use regression analyses to predict the dependent variables at the second measurement to test the first and third hypothesis, taking into account the scores of the same variable at the first measurement to control for autoregressive effects. With regard to L2, the dependent variables were word reading fluency (OMT), loanword reading fluency, vocabulary, orthographic knowledge, and orthographic awareness. With the exception of orthographic awareness and fluency of loanword reading (tested only at T2), the score of the same variable at T1 was entered first, followed by age (in months) and Dutch vocabulary to control for general effects. The dummy variable bilingual versus single language instruction was added in the last step. The same procedure was followed with the Dutch variables, namely, general word reading 
fluency (EMT, multisyllabic word reading fluency (DMT), reading comprehension, orthographic knowledge and orthographic awareness. Again, with the exception of L1 orthographic awareness (tested only at T2), the score of the same variable at $\mathrm{T} 1$ was entered first, followed by age and Dutch vocabulary to control for general effects.

\section{Results}

Differences between the bilingual and monolingual groups at T1 and T2

Table 1 shows the results of the English tests at T1 and T2. As expected, significant differences were found between the two groups for the measures of English vocabulary and L2 word reading fluency (OMT) at both measurements. The group differences on measures of loanword reading fluency and L2 orthographic awareness were significant at T2 (only measured at that time). Contrary to expectations, the performance on L2 orthographic knowledge of the two groups was comparable at $\mathrm{T} 1$ and $\mathrm{T} 2$.

Table 2 shows the results of the Dutch tests at the two measurements. The results at T1 confirmed that the two groups were comparable with regard to L1 phoneme awareness, vocabulary, orthographic knowledge, and on the general L1 word reading fluency task (EMT). The bilingual instruction group performed better than the single language instruction group on L1 multisyllabic word reading fluency (DMT), and on L1 reading comprehension. At T2, there was still no difference between the groups on general L1 word reading fluency (EMT), and the difference in L1 reading comprehension had disappeared. In addition to the repeated difference in multisyllabic word reading fluency in L1 (DMT), the bilingual group was better at T2 on L1 orthographic knowledge, but not on L1 orthographic awareness (measured at T2

Table 1 Means, SDs and main effects of the two groups on the English tests at T1 and T2

\begin{tabular}{|c|c|c|c|c|c|c|}
\hline & \multicolumn{2}{|c|}{ Bilingual (23) } & \multicolumn{2}{|c|}{ Monolingual (23) } & \multirow{2}{*}{$\begin{array}{l}\text { MANOVA } \\
F(1,44)\end{array}$} & \multirow{2}{*}{$\begin{array}{l}\text { Effect size } \\
\eta_{p}^{2}\end{array}$} \\
\hline & $M$ & SD & $M$ & $\mathrm{SD}$ & & \\
\hline \multicolumn{7}{|l|}{ Variables $\mathrm{T} 1(\max )$} \\
\hline English vocabulary (69) & 28.30 & 9.99 & 22.09 & 7.29 & $5.81 *$ & .12 \\
\hline L2 word reading fluency OMT (120) & 19.39 & 13.29 & 8.30 & 6.69 & $12.78^{* *}$ & .23 \\
\hline L2 orthographic knowledge (40) & 22.57 & 4.69 & 20.74 & 4.05 & $2.00^{n s}$ & .04 \\
\hline \multicolumn{7}{|l|}{ Variables T2 (max) } \\
\hline English vocabulary (69) & 40.00 & 6.92 & 25.39 & 7.19 & $49.32 * *$ & .53 \\
\hline L2 word reading fluency OMT (120) & 27.00 & 14.66 & 14.04 & 10.07 & $12.21 * *$ & .22 \\
\hline Loanword reading fluency (116) & 35.48 & 13.23 & 24.09 & 15.57 & $7.15^{*}$ & .14 \\
\hline L2 orthographic knowledge (40) & 26.65 & 5.76 & 24.78 & 3.50 & $1.77^{n s}$ & .04 \\
\hline L2 orthographic awareness (17) & 14.39 & 1.27 & 11.65 & 3.26 & $14.13^{* *}$ & .24 \\
\hline
\end{tabular}

Maximum score of the different tests is in parenthesis

Note: $* p<.05, * * p<.01$, ns not significant 
Table 2 Means, SDs and main effects of the two groups on the Dutch tests at T1 and T2

\begin{tabular}{|c|c|c|c|c|c|c|}
\hline & \multicolumn{2}{|c|}{ Bilingual (23) } & \multicolumn{2}{|c|}{ Monolingual (23) } & \multirow{2}{*}{$\begin{array}{l}\text { MANOVA } \\
F(1,44)\end{array}$} & \multirow{2}{*}{$\begin{array}{l}\text { Effect } \\
\text { size } \\
\eta_{p}^{2}\end{array}$} \\
\hline & $M$ & $\mathrm{SD}$ & $M$ & SD & & \\
\hline \multicolumn{7}{|l|}{ Variables T1 (max) } \\
\hline Dutch vocabulary CITO (50) & 41.57 & 4.23 & 42.30 & 3.89 & $.38^{n s}$ & .01 \\
\hline Phoneme awareness (30) & 19.35 & 4.29 & 19.04 & 4.32 & $.06^{n s}$ & .001 \\
\hline L1 word reading fluency EMT (116) & 46.47 & 16.44 & 37.96 & 15.94 & $3.38^{n s}$ & .07 \\
\hline $\begin{array}{l}\text { L1 multiple-syllable word reading fluency } \\
\text { DMT (150) }\end{array}$ & 47.09 & 21.25 & 34.09 & 22.22 & $4.11^{*}$ & .085 \\
\hline L1 orthographic knowledge (40) & 25.83 & 3.76 & 25.61 & 6.05 & $0.02^{n s}$ & .00 \\
\hline L1 reading comprehension & 21.17 & 2.25 & 24.48 & 5.81 & $6.46^{*}$ & .13 \\
\hline \multicolumn{7}{|l|}{ Variables T2 (max) } \\
\hline L1 word reading fluency EMT (116) & 57.57 & 12.76 & 51.30 & 15.89 & $2.17^{n s}$ & .05 \\
\hline $\begin{array}{l}\text { L1 multiple-syllable word reading fluency } \\
\text { DMT (150) }\end{array}$ & 69.74 & 19.24 & 54.78 & 22.13 & $5.98 *$ & .12 \\
\hline L1 orthographic knowledge (40) & 32.48 & 3.06 & 29.87 & 4.93 & $4.64 *$ & .10 \\
\hline L1 orthographic awareness (17) & 15.17 & 1.67 & 14.26 & 3.18 & $1.49^{n s}$ & .03 \\
\hline L1 reading comprehension & 29.22 & 12.21 & 24.83 & 13.13 & $1.38^{n s}$ & .03 \\
\hline German orthographic knowledge (20) & 10.00 & 3.00 & 8.48 & 2.39 & $3.62^{n s}$ & .08 \\
\hline German orthographic awareness (17) & 9.87 & 2.77 & 9.96 & 1.75 & $0.02^{n s}$ & .00 \\
\hline
\end{tabular}

Maximum score of the different tests is in parenthesis

Note: $* p<.05$, ns not significant

only). The L3 tests of German orthographic knowledge and orthographic awareness (T2 only) did not reveal differences between the groups.

Differences between L1 and L2 word reading fluency

The measures of word reading fluency (OMT and EMT) allowed for a direct comparison between Dutch and English because they can be considered to be equivalent tests with lists of words of increasing length, the score of words read correctly in $1 \mathrm{~min}$ as score, and comparable national norms. Figure 1 shows the results of the bilingual group at both measurements. There was a main effect of time (Greenhouse-Geisser statistics) $F(1,22)=51.43, \mathrm{p}<.01, \eta_{p}^{2}=.70$, and language $F(1,22)=285.71, \mathrm{p}<.01, \eta_{p}^{2}=.93$. There was no interaction effect between time and language: $F(1,22)=2.49, \mathrm{p}=.13$.

Effect of bilingual instruction on English measures at T2

In order to check whether there was a difference in progress on English skills between $\mathrm{T} 1$ and T2, a series of regression analyses was done. To predict L2 word reading fluency (OMT) at $\mathrm{T} 2$, OMT at $\mathrm{T} 1$ was entered first to control for the 


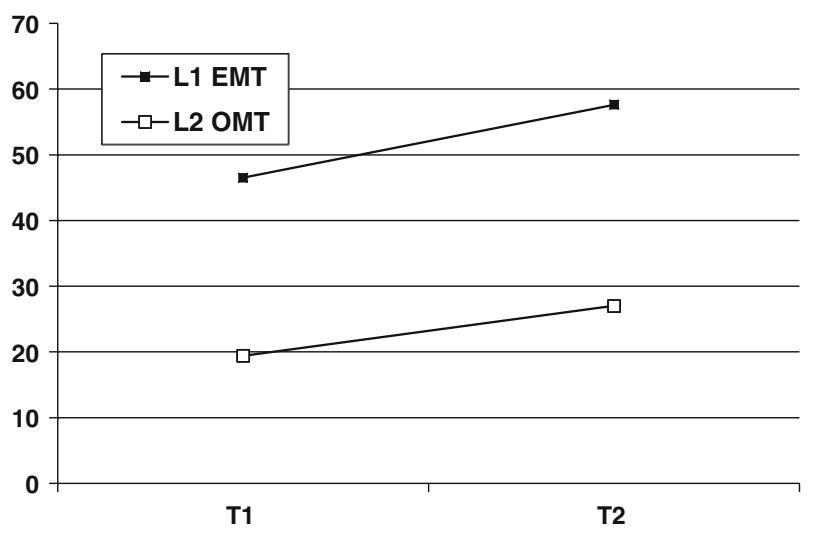

Fig. 1 Progress of word reading fluency in Dutch and English of the bilingual group between T1 (halfway through Grade 2) and T2 (halfway through Grade 3)

autoregressive effect. Next, the general control variables used in the analysis at T1 (Table 3) were entered: age and Dutch vocabulary. Although the difference in general L1 word reading fluency (EMT) at T1 was not significant (Table 1), it was, on average, quite substantial between the groups. To control for its effects, L1 EMT at $\mathrm{T} 1$ was entered in the next step, followed by the dummy variable bilingual versus single language instruction in the last step. As can be seen in Table 3, the autoregressive variable counted for most of the variance $(58.8 \%)$, and there was no significant contribution by other variables to the total of $67.5 \%$.

There was, however, a significant contribution of the dummy variable to English vocabulary at T2. After controlling for the autoregressive effect (English vocabulary at T1: $14.8 \%$ ), age $(8.2 \%)$ and Dutch vocabulary (ns), bilingual versus single language instruction added $36.2 \%$ to the total of $60.5 \%$ (Table 4), indicating a significant difference in progress between $\mathrm{T} 1$ and $\mathrm{T} 2$ under influence of bilingual instruction.

There was no contribution of bilingual versus single language instruction to L2 orthographic knowledge at $\mathrm{T} 2$, which was mainly predicted by orthographic knowledge at T1 (24.7\% out of a total of $25.6 \%)$ (details not shown). Of the two L2

Table 3 Variance ( $R^{2}$ change) in predicting English fluency of word reading (OMT) at T2 explained by English word reading fluency, age, Dutch vocabulary and Dutch word reading fluency at T1, and bilingual versus single language instruction

\begin{tabular}{llccccc}
\hline Step & Variable & $R$ & $R^{2}$ change $(\%)$ & $F$ change & $\beta$ & \multicolumn{1}{l}{$t$} \\
\hline 1 & Autoregressor L2 OMT T1 & .77 & 58.8 & $62.82^{* *}$ & .42 & $2.52^{*}$ \\
2 & Age T1 & .77 & 0.9 & $.96^{n s}$ & .09 & $.94^{n s}$ \\
3 & Dutch vocabulary CITO T1 & .79 & 3.2 & $3.57^{n .} .066$ & .19 & $2.06^{*}$ \\
4 & L1 word reading fluency EMT T1 & .81 & 2.3 & $2.66^{n s}$ & .30 & $1.95^{n s}$ \\
5 & Bilingual versus single language instruction & .82 & 2.3 & $2.77^{n s}$ & .18 & $1.66^{n s}$ \\
Total & & & 67.5 & & & \\
\hline
\end{tabular}

Note: $* p<.05, * * p<.01$, ns not significant 
Table 4 Variance ( $R^{2}$ change) in predicting English vocabulary at T2 explained by English vocabulary, age and Dutch vocabulary at T1, and bilingual versus single language instruction

\begin{tabular}{llccccc}
\hline Step & Variable & $R$ & $R^{2}$ change $(\%)$ & $F$ change & $\beta$ & $t$ \\
\hline 1 & Autoregressor English vocabulary T1 & .38 & 14.8 & $7.61^{* *}$ & .13 & $1.20^{n s}$ \\
2 & Age T1 & .48 & 8.2 & $4.58^{*}$ & .19 & $1.85^{n s}$ \\
3 & Dutch vocabulary CITO T1 & .49 & 1.3 & $0.73^{n s}$ & .16 & $1.63^{n s}$ \\
4 & Bilingual versus single language instruction & .78 & 36.2 & $37.47^{* *}$ & .65 & $6.12^{* *}$ \\
Total & & & 60.5 & & & \\
\hline
\end{tabular}

Note: $* p<.05, * * p<.01, n s$ not significant

tasks that were measured at T2 only, fluency of loanword reading was mainly predicted by fluency of word reading in L2 (OMT) at T1 (40.5\% out of a total of $42 \%$ ) (details not shown). Orthographic awareness in L2, however, was not predicted by L2 orthographic knowledge at T1 (entered to control for differences in L2 orthographic knowledge at the start of the measurement period), or by the control variables age and Dutch vocabulary, but only by bilingual versus single language instruction which explained $26.2 \%$ out of a total of $29.6 \%$ (Table 5).

Effect of bilingual instruction on Dutch measures at T2

At T2 there was no significant contribution of the dummy variable to general L1 word reading fluency EMT after EMT at T1 was entered (explaining $51.8 \%$ of $52.8 \%$ ), followed by age and Dutch vocabulary. The same results were found with L1 multisyllabic word reading fluency measured by the DMT (the autoregressive effect was $74.3 \%$ out of $75.5 \%$ of the explained variance) (details not shown). However, there still was a contribution to L1 reading comprehension at $\mathrm{T} 2: 7.7 \%$ out of $19.8 \%$ whereas L1 reading comprehension at T1 did not contribute significantly, and the contribution of L1 vocabulary at T1 just missed significance (Table 6).

There was no contribution to L1 orthographic awareness at T2 of any of the variables. L1 orthographic knowledge at T2 was, however, not only explained by

Table 5 Variance $\left(R^{2}\right.$ change) in predicting English orthographic awareness at T2 explained by English orthographic knowledge, age and Dutch vocabulary at T1, and bilingual versus single language instruction

\begin{tabular}{|c|c|c|c|c|c|c|}
\hline Step & Variable & $R$ & $R^{2}$ change $(\%)$ & $F$ change & $\beta$ & $t$ \\
\hline 1 & L2 orthographic knowledge T1 & .07 & 0.5 & $0.23^{n s}$ & -.19 & $-1.44^{n s}$ \\
\hline 2 & Age $\mathrm{T} 1$ & .16 & 1.9 & $0.83^{n s}$ & .01 & $0.10^{n s}$ \\
\hline 3 & Dutch vocabulary CITO T1 & .18 & 1.0 & $0.42^{n s}$ & .15 & $1.10^{n s}$ \\
\hline 4 & Bilingual versus single language instruction & .54 & 26.2 & $15.27 * *$ & .54 & $3.91 * *$ \\
\hline Total & & & 29.6 & & & \\
\hline
\end{tabular}

Note: $* * p<.01$, ns not significant 
Table 6 Variance $\left(R^{2}\right.$ change) in predicting Dutch reading comprehension at T2 explained by Dutch reading comprehension, age and Dutch vocabulary at T1, and bilingual versus single language instruction

\begin{tabular}{|c|c|c|c|c|c|c|}
\hline Step & Variable & $R$ & $R^{2}$ change $(\%)$ & $F$ change & $\beta$ & $t$ \\
\hline 1 & Autoregressor $\mathrm{L} 1$ reading comprehension $\mathrm{T} 1$ & .27 & 7.0 & $3.33^{n s}$ & 0.32 & $2.06^{*}$ \\
\hline 2 & Age T1 & .27 & 0.4 & $0.19^{n s}$ & 0.01 & $0.06^{n s}$ \\
\hline 3 & Dutch vocabulary CITO T1 & .39 & 7.8 & $3.89^{n s .055}$ & 0.28 & $2.01^{n s} .051$ \\
\hline 4 & Bilingual versus single language instruction & .48 & 7.7 & $4.12^{*}$ & 0.31 & $2.03^{*}$ \\
\hline Total & & & 19.8 & & & \\
\hline
\end{tabular}

Note: $* p<.05, n s$ not significant

Table 7 Variance ( $R^{2}$ change) in predicting Dutch orthographic knowledge at T2 explained by Dutch orthographic knowledge, age and Dutch vocabulary at $\mathrm{T} 1$, and bilingual versus single language instruction

\begin{tabular}{|c|c|c|c|c|c|c|}
\hline Step & Variable & $R$ & $R^{2}$ change $(\%)$ & $F$ change & $\beta$ & $t$ \\
\hline 1 & Autoregressor L1 orthographic knowledge T1 & .44 & 18.9 & $10.25 * *$ & 0.32 & $2.06^{*}$ \\
\hline 2 & Age T1 & .45 & 1.6 & $0.89^{n s}$ & 0.01 & $0.06^{n s}$ \\
\hline 3 & Dutch vocabulary CITO T1 & .46 & 0.1 & $0.06^{n s}$ & 0.28 & $2.01^{\text {ns } .051}$ \\
\hline 4 & Bilingual versus single language instruction & .54 & 7.8 & $4.48^{*}$ & 0.31 & $2.03 *$ \\
\hline Total & & & 28.5 & & & \\
\hline
\end{tabular}

Note: $* p<.05, * * p<.01, n s$ not significant

the same variable at $\mathrm{T} 1$ (18.9\%), but also by bilingual versus single language instruction ( $7.8 \%$ out of a total of $28.5 \%$ ) (Table 7 ).

Effect of bilingual instruction on German measures at T2

To determine whether instruction in English leads to a more general knowledge or awareness of orthographic features, these skills in German were measured at T2. However, as can be seen in Table 2 it is clear that there were no group differences on orthographic knowledge or orthographic awareness in the third language, German, in which no instruction had been given.

\section{Discussion}

It may be concluded that the findings support the expectation that in comparison with single language instruction, bilingual instruction has a positive influence on L2 English reading and vocabulary, indicated by group differences with single language instruction on all L2 reading and vocabulary variables at both measurement waves, with the exception of orthographic knowledge. In addition, predictions controlled for general and specific developmental variables revealed a significant contribution of bilingual instruction to L2 vocabulary and L2 orthographic awareness. With regard to L2 vocabulary, the difference in progress between 
measurements was particularly impressive: after controlling for the autoregressive effect of L2 vocabulary at T1 (14.8\%), the contribution was no less than $36.2 \%$ of a total of $60.5 \%$ (Table 4). Between measurements, bilingual instruction did not affect the difference in L2 word reading fluency (OMT) already present at T1, or difference in L2 orthographic knowledge (absent at T1). L2 loanword reading fluency (measured only at T2) was predicted by general reading fluency at T1.

The second expectation that word reading fluency would be easier to acquire in Dutch with its relatively transparent orthography in comparison to English with its deep orthography was also supported by the results. In terms of words read correctly per minute, the bilingual group did far better in L1 than in L2, in line with the conclusions of Seymour et al. (2003). In addition to this indication of scriptdependency, the high correlations between L1 EMT and L2 OMT at both measurements (.80 and .70, respectively, for the total group) indicate the influence of central processing, supporting the conclusions of Geva and Siegel (2000). However, there was no difference in progress between L1 and L2 word reading fluency within the bilingual group between measurements. One possible explanation might be that the focus in that period was still much on communication, which resulted in both the large progress in L2 vocabulary and less progress in L2 word reading fluency.

The third expectation-benefits to L1 due to bilingual instruction-was partly supported. Bilingual instruction contributed significantly to L1 orthographic knowledge and L1 reading comprehension at T2 after controlling for autoregressive effects. In contrast, L1 multiple-syllable word reading fluency (DMT) at T2 was only predicted by the same variable at $\mathrm{T} 1$, and there was no indication for a more general effect of generalization to orthographic awareness in L1, or to orthographic knowledge of a language (German) in which no instruction had been given. Still, the increased difference in L1 orthographic knowledge in Dutch between measurements suggests that understanding the logographic principles which appear less frequently in Dutch than in English but are nevertheless present in quite a few Dutch multisyllabic words, is stimulated by bilingual instruction which includes English, as has been proposed by Bialystok et al. (2005) and Morfidi et al. (2007). The difference in L1 reading comprehension may also be related to an improved skill in higher-order orthographic processing of the bilingual group. However, a larger scaled study is necessary to investigate the issue of generalization of orthographic knowledge from second to first language, including the relationship to reading comprehension.

The results of the present study support the conclusion that development in L1 is not slowed down by concurrent instruction and practice in English (Geva \& Siegel, 2000). Instead, there are indications of a positive effect of bilingual instruction on L1, supporting the suggestions of Bialystok et al. (2005). At the two measurement waves, all four significant differences on Dutch tests were in favour of the bilingual group: multisyllabic word reading fluency (both occasions), reading comprehension (measurement 1), and orthographic knowledge (measurement 2). To support the notion of comparability of the two groups on basic skills, there were no differences on L1 phoneme awareness, general L1 word reading fluency (EMT), and L1 vocabulary. To our knowledge this is the first study to show that concurrent 
instruction of L1 Dutch and L2 English promotes reading acquisition and vocabulary of young students in both languages. It is important to note that, because the total time spent on reading instruction and practice of L1 and L2 in the bilingual group was about the same as the total time spent in the monolingual group on L1 alone, the differences in skills cannot be attributed to a significant difference in instruction and practice time.

The finding that there were no differences on the English orthographic knowledge tasks on both occasions is puzzling. At the first measurement, the averages of both groups were at chance level, and at the second measurement the achievement in both groups was only slightly better. Although it may be possible that the monolingual group gathered as much English orthographic knowledge in everyday life as the bilingual group, another possible explanation is that the lack of differences is related to the psychometric quality of the task, in particular at this age. The same test, originating from a study described by Olson et al. (1994), has been used successfully in a Dutch study with adolescents (Morfidi et al., 2007), showing both a significant difference between poor and good readers and a modest contribution to the prediction of L1 word reading fluency. The findings of the present study (Table 1) suggest that, at least at this age, orthographic awareness tasks are a better choice (see also Siegel et al., 1995). However, an alternative explanation is that the English instruction of the bilingual group did not focus on orthographic features of words, i.e., spelling patterns. As described in the method section, spelling was not attended to earlier than in Grade 3. Possibly, the experience was too brief to affect word-specific knowledge at the second measurement which was halfway through Grade 3.

It may be clear that the present study has limitations because of the small samples and the lack of experimental control from the start of the bilingual instruction and practice in Kindergarten and, in particular, when reading instruction began in Grade 1. In addition, no conclusions can be made with regard to L2 reading comprehension because no test was included in the study for practical reasons. We refrained from attempting to develop such a test because of obvious problems with equivalence that we also encountered in an earlier study (Morfidi et al., 2007). Another limitation is that, in terms of explained variance, large differences occur between the predictions. The total of variance of the general word reading fluency tests (OMT, EMT, DMT) explained at T2 was high, in particular due to the contribution of the same variable at T1. With regard to the other variables, only L2 vocabulary at T2 had a substantial percentage of explained variance $(60.5 \%$; Table 4$)$. Because in this case there was control for the autoregressive effect, the large contribution of the instruction variable may be regarded as the most significant finding of the study. The results of the analyses of the other variables did not indicate a total of explained variance above $30 \%$, suggesting that other, not measured, variables may have had more influence.

Notwithstanding these limitations, the general conclusion may be drawn that the results of the present study support the assumption that concurrent instruction in Dutch and English has positive effects on the acquisition of L2 English and L1 Dutch. 
Acknowledgments The authors wish to thank Dr. R. I. Nicolson (University of Sheffield, UK) for providing the normative data of the OMT and three anonymous reviewers for their comments which were extremely useful to improving the paper.

Open Access This article is distributed under the terms of the Creative Commons Attribution Noncommercial License which permits any noncommercial use, distribution, and reproduction in any medium, provided the original author(s) and source are credited.

\section{Appendix A}

1. The items included in the Dutch orthographic awareness task were the following: Practice: purf-purf, scham-sgam, nerp-nepr. Test: zwap-zjap, chlijpglijp, barc-bark, jors-jorz, minc-mins, hitt-hilt, zpak-spak, gidt-gitd, tisp-tisn, haft-hafl, gwan-gran, jilv-jilf, noght-nocht, znat-snat, serm-semr, scken-schen, gorm-ghorm.

2. The items included in the English orthographic awareness task were the following: Practice: serb-sebr, zleg-sleg, gwan-gran. Test: filv-filk, telz-teld, powl-lowp, dlun-lund, fant-tanf, mird-midr, swed-zwed, wolh-wolt, moke-moje, jofy-fojy, cnif-crif, bnad-blad, hift-hifl, gsup-gnup, nitl-nilt, clid-cdil, gish-gisj.

3. The items included in the German orthographic awareness task were the following: Practice: barf-barv, tarp-tapr, sund-dusn. Test: dolz-dolj, tuss-tush, schal-sjal, pehr-pehs, lükk-lück, suhr-sucr, lett-ledd, abst-abct, sjnul-schnul, narz-narc, mech-megh, latl-lath, dalch-dalcg, disch-disjh, klöd-mlöd, sädl-säcl, pflan-plfan.

Note. The words in italic are the correct responses.

\section{Appendix B}

The items included in the German orthographic knowledge task were the following: Practice: Apfel-Appel-Affel, Glaas-Glas-Glass, Milch-Milg-Mielch. Test: Fuss-Foes-Voess, Jar-Jahr-Jaer, Tur-Tür-Tuur, Schoe-Sjoe-Schuh, HolzHolts-Holtss, zwarz-schwarz-swarts, noij-neu-neuj, Oopst-Oopst-Obst, krannkkrank-cranck, Riese-Riejse-Riece, Uhhr-Uhr-Oer, Bein-Bain-Bajn, Urlaup-Urlaub-Oerlaup, Immer-Iemer-Imer, Koph-Kopf-Koppf, Tish-Tisch-Tiesj, SchtoelStuhl-Stoel, Boeg-Boech-Buch, Oor-Ohr-Oohr, Hund-Hoend-Hunt.

Note. The words in italic are the correct responses.

\section{References}

Assink, E. M. H., \& Kattenberg, G. (1994). Higher-order linguistic influences on development of orthographic knowledge: Illustrations from spelling problems in Dutch and assessment tools. In V. W. Berninger (Ed.), The varieties of orthographic knowledge. Vol. 1. Theoretical and developmental issues (pp. 111-136). Dordrecht, The Netherlands: Kluwer.

Bekebrede, J., van der Leij, A., \& Share, D. L. (2009). Dutch dyslexic adolescents: Phonological core variable orthographic differences. Reading and Writing: An Interdisciplinary Journal, 22, 133-165. 
Bialystok, E., Luk, G., \& Kwan, E. (2005). Bilingualism, biliteracy, and learning to read: Interactions among languages and writing systems. Scientific Studies of Reading, 9, 43-61.

Borgwaldt, S., Hellwig, F. M., \& de Groot, A. M. B. (2005). Onset entropy matters-Letter-to-phoneme mappings in seven languages. Reading and Writing: An Interdisciplinary Journal, 18, 211-229.

Brus, B. T., \& Voeten, M. J. M. (1973). Een-Minuut-Test [One-Minute-Test]. Nijmegen, The Netherlands: Berkhout.

Buis, P., \& Charles, A. (1996). Dyslexie in het Voortgezet Onderwijs [Dyslexia in secondary education]. Utrecht, The Netherlands: Brains.

Cisero, C., \& Royer, J. M. (1995). The development and cross-language transfer of phonological awareness. Contemporary Educational Psychology, 20, 275-303.

Cohen, J. (1977). Statistical power analysis for the behavioral sciences. New York: Academic Press.

Comeau, L., Cormier, P., Grandmaison, E., \& Lacroix, D. (1999). A longitudinal study of phonological processing skills in children learning to read in a second language. Journal of Educational Psychology, 9, 29-43.

Dunn, L. M., \& Dunn, L. (1981). Peabody picture vocabulary test-revised. Circle Pines, MN: American Guidance Service.

Durgunoğlu, A. Y., Nagy, W., \& Hancin-Bhatt, B. J. (1993). Cross-language transfer of phonological awareness. Journal of Educational Psychology, 85(3), 543-565.

Fawcett, A. J., \& Nicolson, R. I. (1996). Dyslexia screening test. London: The Psychological Corporation.

Ganschow, L., Sparks, R. L., Javorsky, J., Pohlman, J., \& Bishop-Marbury, A. (1991). Identifying native language difficulties among foreign language learners in college: A "foreign" language learning disability? Journal of Learning Disabilities, 24, 530-541.

Geva, E., \& Siegel, L. (2000). Orthographic and cognitive factors in the concurrent development of basic reading skills in two languages. Reading and Writing: An Interdisciplinary Journal, 12, 1-30.

Gottardo, A., Yan, B., Siegel, L. S., \& Wade-Woolley, L. (2001). Factors related to English reading performance in children with Chinese as a first language: More evidence of cross-language transfer of phonological processing. Journal of Educational Psychology, 93, 530-542.

Horsley, T. M. (2005). Not all dyslexics are created equal: Neurocognitive evidence. Unpublished doctoral dissertation, Free University, Amsterdam.

Lindsey, K. A., Manis, F. R., \& Bailey, C. (2003). Prediction of first-grade reading in Spanish-speaking English- language learners. Journal of Educational Psychology, 95(3), 482-494.

Moelands, F., Kamphuis, F., \& Verhoeven, L. (2003). Verantwoording Drie-Minuten-Toets [Justification of the three-minutes-test]. Arnhem, The Netherlands: Cito.

Morfidi, E., van der Leij, A., de Jong, P. F., Scheltinga, F., \& Bekebrede, J. (2007). Reading in two orthographies: A cross-linguistic study of Dutch average and poor readers who learn English as a second language. Reading and Writing: An Interdisciplinary Journal, 20, 753-784.

Olson, R. K., Forsberg, H., Wise, B., \& Rack, J. P. (1994). Measurement of word recognition, orthographic, and phonological skills. In G. R. Lyon (Ed.), Frames of reference for the assessment of learning disabilities (pp. 243-277). Baltimore: Brookes Publishing Co.

Riccio, C. A., Amado, A., Jimenez, S., Hasbrouck, J. E., Imhoff, B., \& Denton, C. (2001). Crosslinguistic transfer of phonological processing: Development of a measure of phonological processing in Spanish. Bilingual Research Journal, 25, 416-436.

Schijf, G. M. (2006). Leenwoordenlijst Engels [Loanwords English]. Retrieved December 1, 2006 from www.muiswerk.nl/downdoc/leenwoorden-2006.doc.

Seymour, P., Aro, M., \& Erskine, J. (2003). Foundation literacy acquisition in European orthographies. British Journal of Psychology, 94, 143-174.

Share, D. L. (2008). On the anglocentricities of current reading research and practice: The perils of overreliance on an "outlier" orthography. Psychological Bulletin, 134, 584-615.

Siegel, L. S., Share, D. L., \& Geva, E. (1995). Evidence for superior orthographic skills in dyslexics. Psychological Science, 6, 250-254.

Staphorsius, G., \& Krom, R. (1998). Toetsen Begrijpend Lezen [Reading comprehension tasks]. Arnhem, The Netherlands: Cito.

Staphorsius, G., Krom, R., Kleintjes, F., \& Verhelst, N. (2004). Toetsen Begrijpend lezen: Verantwoording [Reading comprehension tasks: Justification]. Arnhem, The Netherlands: Cito.

Stevens, J. P. (2002). Applied multivariate statistics for the social sciences. Mahwah, NJ: Lawrence Erlbaum Associates.

Tabachnick, B. G., \& Fidell, L. S. (2007). Using multivariate statistics (5th ed.). Upper Saddle River: Pearson Education Inc. 
van den Bos, K. P., lutje Spelberg, H. C., Scheepstra, A. J. M., \& de Vries, J. (1994). De Klepel. Vorm A en B. Een test voor de leesvaardigheid van pseudowoorden. Verantwoording, handleiding, diagnostiek en behandeling. [The Klepel. Form A and B. A test of reading pseudowords]. Nijmegen, The Netherlands: Berkhout.

van den Bosch, A., Content, A., Daelemans, W., \& de Gelder, B. (1994). Measuring the complexity of writing systems. Journal of Quantitative Linguistics, 1, 178-188.

van der Leij, A., \& Morfidi, E. (2006). Core deficits and variable differences in Dutch poor readers learning English. Journal of learning disabilities, 39, 74-90.

van der Leij, A., \& van Daal, V. H. P. (1999). Automatization aspects of dyslexia: Speed limitations in word identification, sensitivity to increasing task demands, and orthographic comprehension. Journal of Learning Disabilities, 32, 417-428.

Verhoeven, L. (1993a). Woordenschat [Vocabulary]. Arnhem, The Netherlands: CITO.

Verhoeven, L. (1993b). Lezen met Begrip 1-Schaal Betekenis Relaties [Comprehension-scale relations between meanings]. Arnhem, The Netherlands: CITO.

Verhoeven, L. (1995). Drie Minuten Toets Handleiding. [Three Minutes Test Manual]. Arnhem, The Netherlands: CITO. 